\title{
Caracterização do óleo das sementes de Pachira aquatica Aublet para aproveitamento alimentar
}

\begin{abstract}
Neuza JORGE ${ }^{1}$, Débora Maria Moreno LUZIA²
RESUMO

Os frutos de Pachira aquatica Aublet apresentam sementes comestíveis com características organolépticas muito apreciadas pelas populaçóes amazônicas, sendo pouco utilizados em outras regióes. Este trabalho teve como objetivo caracterizar as sementes quanto à composiçấo centesimal e determinar as características físico-químicas e perfil de ácidos graxos. A determinação da composição centesimal das sementes (teores de umidade, lipídios, proteínas, cinzas e carboidratos) e análises do óleo extraído das mesmas (ácidos graxos livres, índices de peróxido, iodo, refração, saponificação, ponto de fusão e perfil de ácidos graxos) foram realizadas seguindo metodologia oficial. O teor de óleo nas sementes 38,39\% demonstrou que estas têm potencial para aproveitamento industrial. Das características físico-químicas analisadas, o óleo extraído das sementes apresentou 39,2\% de ácidos graxos livres (expresso em \% ácido oleico), índice de iodo de $27,4 \mathrm{~g} \mathrm{I}_{2} .100 \mathrm{~g}^{-1}$, índice de saponificação de 208,0 mg.KOH g ${ }^{-1}$, índice de refração $\left(40^{\circ} \mathrm{C}\right)$ de 1,4569 e ponto de fusão de $41,9^{\circ} \mathrm{C}$. Quanto à composição de ácidos graxos do óleo predominaram os ácidos palmítico $(44,93 \%)$, oleico $(39,27 \%)$ e linoleico $(11,35 \%)$. Tal fato favorece o uso deste óleo como matéria-prima para as indústrias alimentícia, farmacêutica e de cosméticos.
\end{abstract}

PALAVRAS-CHAVE: ácidos graxos, frutos, medidas físico-químicas.

\section{Characterization of seed oil Pachira aquatica Aublet for food utilization}

\section{ABSTRACT}

The fruits of Pachira aquatica Aublet present edible seeds with organoleptic characteristics much appreciated by peoples in the Amazon, with little being used in other regions. This study aimed to characterize the seeds and to determine the composition and physicochemical characteristics and fatty acid profile. Determining the composition of the seeds (moisture, lipids, proteins, carbohydrates and ash) and analysis of oil extracted from them (free fatty acids, peroxide, iodine, refractive index, saponification value, melting point and fatty acid profile) was performed following the official methodology. The oil content in the seeds $38.39 \%$ showed that these have potential for industrial use. The physical and chemical analysis, the oil extracted from the seeds showed $39.2 \%$ of free fatty acids (\% oleic acid), iodine value of $27.4 \mathrm{I}_{2} .100 \mathrm{~g}^{-1}$, saponification number of $208.0 \mathrm{mg} . \mathrm{KOH} \mathrm{g}^{-1}$, refractive index $\left(40^{\circ} \mathrm{C}\right)$ of 1.4569 and melting point of $41.9^{\circ} \mathrm{C}$. Regarding the composition of fatty acids palmitic predominated oil (44.93\%), oleic (39.27\%) and linoleic (11.35\%). This fact favors the use of oil as raw material for the food, pharmaceutical and cosmetic industries.

KEYWORDS: fatty acids, fruits, physicochemical measurements.

1 njorge@ibilce.unesp.br

2 UNESP. deboramaria_moreno@yahoo.com.br 
Caracterização do óleo das sementes de Pachira aquatica Aublet para aproveitamento alimentar

\section{INTRODUÇÃO}

A Pachira aquática Aublet (família Bombacaceae), vulgarmente conhecida como munguba, castanheira-domaranhão, castanheira, cacau-selvagem, é uma árvore nativa do sul do México até o norte da América do Sul, na área compreendida pela floresta amazônica, onde pode ser encontrada frequentemente em terrenos alagadiços e matas ciliares, entretanto, apresenta a característica de facilmente se adaptar às condições edáficas e climáticas diversas (Peixoto e Escudeiro, 2002; Paula et al. 2006).

Segundo Lorenzi (1992), a Pachira aquática Aublet foi introduzida em arborização urbana na segunda metade do século XIX pelo botânico e paisagista francês Glaziou. Nos estados de São Paulo e Rio de Janeiro se expandiu graças aos trabalhos paisagísticos de Roberto Burle Marx na década de 60. É uma árvore de rápido crescimento e nas condiçôes edafo-climáticas apresenta porte médio.

A espécie é adaptável ao cultivo e produz uma grande quantidade de frutos com sementes comestíveis com características organolépticas muito apreciadas pelas populaçôes amazônicas, no entanto é pouca utilizada em outras regiôes do Brasil. Os frutos sáo comestíveis e podem ser consumidos de diversas maneiras: crus, assados, cozidos ou torrados e transformados em farinha. Segundo Cetto e Heinrich (2005), o consumo de Pachira aquática Aublet pode ter efeito hipoglicemiante no tratamento de diabetes e seus sintomas.

Em estudos realizados por Polizelli et al. (2008) e Lago et al. (1987) foram constatados elevado teor de óleo $(44,1 \%)$ no fruto de Pachira aquática Aublet, sendo o ácido palmítico o seu principal componente. Polizelli et al. (2008) também observaram elevado teor de triptofano, aminoácido precursor de um importante neurotransmissor, a serotonina. Oliveira et al. (2000), estudando a composição e as propriedades nutricionais de sementes, encontraram teores de $53,9 \%$ de óleo e $12,9 \%$ de proteínas.

A composição em ácidos graxos dos alimentos é de grande importância, principalmente os poli-insaturados das famílias ômega-3 e ômega- 6 , aos quais se atribuem numerosos benefícios ao organismo humano. A família ômega-3 (PUFA n-3) representado pelo ácido graxo essencial $\alpha$-linolênico (C18:3 n-3), que por alongamento e dessaturação, geram os ácidos eicosapentaenoico (EPA - C20:5 n-3) e docosahexaenoico (DHA - C22:6 n-3). A família ômega-6 compreende o ácido graxo essencial linoleico, que pode originar o ácido araquidônico (Cahoon et al. 2007; Cahoon e Schmid, 2008).

Epidemiologicamente, os ácidos graxos poli-insaturados ômega-3 mostram efeito benéfico na prevenção de vários tipos de câncer e doenças cardiovasculares. Os ácidos graxos ômega-6 exercem importante papel fisiológico como potentes mediadores da inflamaçấo e efeito benéfico sobre o sistema imune (Harris, 2008; Lavie, 2009).

Os ácidos linoleico e $\alpha$-linolênico estão presentes tanto em espécies vegetais como animais. O óleo de linhaça é considerado, entre os óleos vegetais, a fonte mais rica de ácido $\alpha$-linolênico (57\%). As sementes de soja e girassol contêm entre 50 e $75 \%$ de ácido linoleico e as sementes de canola, soja, gérmen de trigo e nozes contêm entre 7 e $13 \%$ de acido $\alpha$-linolênico (Carrero et al. 2005).

Brum et al. (2009), em estudo realizado com o óleo das sementes da Pachira aquatica Aublet, atingiram resultados promissores para o óleo, visando uma possível aplicação deste para biodiesel.

O estudo da composição das sementes de Pachira aquática Aublet contribuirá com os profissionais da área de alimentos para uma adequada orientação dietética, bem como na obtenção de dados que possam ser utilizados em tabelas de composiçáo centesimal e de ácidos graxos de sua fraçáo lipídica. A obtenção de dados referentes à composiçẫo de alimentos brasileiros tem sido estimulada com o objetivo de reunir informaçóes atualizadas, confiáveis e adequadas à realidade nacional.

Desta maneira, o objetivo deste trabalho foi caracterizar as sementes quanto à composição centesimal e determinação das características físico-químicas e perfil de ácidos graxos do óleo extraído das sementes de Pachira aquática Aublet.

\section{MATERIAL E MÉTODOS}

\section{Material}

\section{Obtenção das sementes}

Os frutos in natura, provenientes de árvores plantadas na regiáo de Franca, norte do estado de São Paulo, foram colhidos diretamente das árvores quando apresentavam abertura espontânea. Em seguida foram levados para estufa de secagem a $40^{\circ} \mathrm{C}$, com circulação forçada de ar, para completar a abertura e a liberação das sementes, com redução de umidade $(<10 \%)$. As sementes, após serem moídas e passadas em peneira vibratória de malha $0,84 \mathrm{~mm}$, para a obtenção de um farelo de granulaçáo homogênea, foram armazenadas em recipientes plásticos, os quais foram vedados com tampas de rosca e devidamente rotulados, para análises posteriores.

\section{Obtenção do óleo}

O óleo foi obtido por extração com éter de petróleo a 40$60^{\circ} \mathrm{C}$ utilizando extrator Soxhlet por 6 horas. Após a extração, o solvente foi evaporado sob pressão reduzida a $60^{\circ} \mathrm{C}$. O óleo obtido foi acondicionado em frasco de vidro âmbar, inertizado 
com nitrogênio gasoso e armazenado em freezer $\left(-18^{\circ} \mathrm{C}\right)$ até o momento das análises.

\section{Métodos de análises}

\section{Composição centesimal das sementes}

- Umidade e Matérias voláteis, por aquecimento a $105^{\circ} \mathrm{C}$ em estufa de ar forçado até atingir peso constante, de acordo com o Método AOCS Ai 275 (2009).

- Matéria Graxa, por extraçáo com éter de petróleo 40-60 ${ }^{\circ} \mathrm{C}$ sobre as sementes secas e moídas empregando extractor Soxhlet, de acordo com o Método AOCS Ai 375 (2009).

- Proteinas ( $N \times$ 6,25), pelo Método de Kjeldahl de acordo com o método descrito pela AOAC 984.13 (2005) empregando catalisador sulfato de cobre.

- Cinzas, por calcinaçáo a $550^{\circ} \mathrm{C}$ de acordo com o Método AOCS Ba 5a-49 (2009).

- Carboidratos e Fibras, por diferença.

\section{Análises do óleo extraído das sementes}

- Ácidos graxos livres, porcentagem de ácidos graxos livres que um óleo contém, expressos como ácido oleico. Foi utilizado o método AOCS Ca 5a-40 (2009).

- Índice de peróxido, miliequivalentes de oxigênio ativo contidos em um quilograma de óleo, calculados a partir do iodo liberado de iodeto de potássio, operando nas condiçốes indicadas no método proposto pela AOCS Cd 8-53 (2009).

- Índice de iodo, é a medida da insaturação de óleos e gorduras e é definido como a quantidade de halogênio em gramas, calculado como iodo absorvido por 100 gramas de amostra. Para esta determinaçáo foi utilizado o método AOCS Cd 1-25 (2009).

- Indice de refração, é característico para cada tipo de óleo, ou seja, está intimamente relacionado com o seu grau de saturação, mas é afetado por outros fatores tais como teores de ácidos graxos livres, oxidação e tratamento térmico. Foi empregado o método proposto pela AOCS Cc 7-25 (2009), mediante refratômetro de Abbe.

- Indice de saponificação, definido pela quantidade em miligramas de hidróxido de potássio necessária para saponificar $1 \mathrm{~g}$ de óleo ou gordura. O material é saponificado por destilação ao refluxo com soluçáo alcóolica de hidróxido de potássio em excesso. A quantidade de álcali consumida é determinada por titulação com ácido clorídrico mais fenolftaleína. $\mathrm{O}$ índice de saponificação é inversamente proporcional ao peso molecular médio dos ácidos graxos dos triacilgliceróis presentes. Utilizouse o método recomendado pela AOCS Cd 3c-91 (2009).

- Ponto de fusáo, expresso em ${ }^{\circ} \mathrm{C}$, foi realizado com auxílio de termômetro e chapa de aquecimento, segundo método proposto pelas normas do Instituto Adolfo Lutz (1985).
- Perfil de ácidos graxos, os ésteres metílicos de ácidos graxos, foram obtidos segundo procedimento descrito por Hartman e Lago (1973). Para a análise cromatográfica, utilizou-se um cromatógrafo a gás marca Varian (Walnut Creek, USA), modelo GC 3900, equipado com detector de ionização de chama, injetor split e amostrador automático. Os compostos foram separados em coluna capilar de sílica fundida CP-Sil 88 $(50 \mathrm{~m} \times 0,25 \mathrm{~mm} \times 0,20 \mathrm{~mm})$. A programação de temperatura da coluna foi iniciada em $50{ }^{\circ} \mathrm{C}$ por 2 minutos, aquecida a $4{ }^{\circ} \mathrm{C} \cdot \mathrm{min}^{-1}$ até $240{ }^{\circ} \mathrm{C}$ e mantida em isoterma durante 20,5 minutos. As temperaturas utilizadas no injetor e no detector foram 230 e $250{ }^{\circ} \mathrm{C}$, respectivamente. As amostras foram injetadas no volume de $1 \mathrm{~mL}$, adotando-se a razáo de divisão de 1:30. O gás de arraste foi o hidrogênio com velocidade linear de $30 \mathrm{~mL} \cdot \mathrm{min}^{-1}$. Os ácidos graxos foram identificados pela comparação dos tempos de retenção de padróes puros de ésteres metílicos de ácidos graxos com os componentes separados das amostras e a quantificação foi feita por normalização de área (\%).

- Tocoferóis, para as determinaçóes dos teores de tocoferóis foi utilizado o método AOCS Ce 8-89 (2009). As análises foram realizadas em cromatografia líquida de alta eficiência (HPLC), com detector de fluorescência, de acordo com as seguintes condiçóes: coluna de sílica de 250 x 4,6 mm com poro de $0,5 \mu \mathrm{m}$, fluxo de $1,2 \mathrm{~mL}$ min- 1 e comprimento de onda de excitação em $290 \mathrm{~nm}$ e de emissão em $330 \mathrm{~nm}$. Utilizou-se como fase móvel uma mistura de $99,5 \%$ de $\mathrm{n}$-hexano e $0,5 \%$ de isopropanol, todos com grau de pureza para CLAE. Pesou-se cerca de $1 \mathrm{~g}$ das amostras de óleo em balão volumétrico de $25 \mathrm{~mL}$, cujo volume foram completados com n-hexano com grau de pureza para CLAE. Os balóes volumétricos foram cobertos com papel alumínio para evitar degradaçấo dos isômeros pela ação da luz. Em seguida, agitaram-se os balóes volumétricos, em agitador mecânico, por 1 minuto e depois procedeu-se à filtraçáo em filtro de $0,45 \mu \mathrm{m}$ e, então, a amostra foi injetada no cromatógrafo. A mistura dos padróes de tocoferol, que continha todos os isômeros foi diluída a partir dos padrôes concentrados e injetada. Os resultados das injeçóes foram registrados em computador pelo software "Galaxie". Os valores das concentraçôes foram calculados em base da área dos picos de excitaçáo da leitura e expressos em valores de cada homólogo separadamente, em termos de mg.kg-1.

\section{RESULTADOS E DISCUSSÃO}

A Tabela 1 apresenta a composição centesimal das sementes de $P$. aquática Aublet, expressa em porcentagem. Dos componentes analisados, observa-se elevado teor para lipídios, com valor de 38,39\% e com quantidades relevantes de carboidratos e fibras, obtidos por diferença. Oliveira et al., (2000) ao estudar sobre as propriedades nutricionais de 
Caracterização do óleo das sementes de Pachira aquatica Aublet para aproveitamento alimentar sementes de $P$. aquática Aublet, encontraram valores para umidade, proteínas, lipídios, carboidratos e cinzas de 6; 12,9; 53,$9 ; 29,7$ e 3,5\%, respectivamente. Tais variaçóes podem ser atribuídas às diferentes condiçóes de cultivo da planta.

Lago et al. (1987) analisando as características-químico nutricionais de espécies de sementes da Amazônia alcançaram para a semente da $P$. aquática Aublet um teor de lipídios $(44,1 \%)$ e proteína $(15,1 \%)$, semelhantes aos índices encontrados neste estudo.

$\mathrm{Na}$ Tabela 2 estão apresentadas as características físicoquímicas do óleo extraído das sementes de P. aquática Aublet.

Observa-se que o óleo apresentou elevada percentagem de ácidos graxos livres (39,2\%), o que pode ser atribuído à ação enzimática de hidrólise das lipases sobre os triacilgliceróis. As porcentagens de ácidos graxos livres variaram entre 0,6\%, para o óleo extraído de fava-de-morcego (Dipteryx lacunifera), e 0,53\%, para o óleo extraído da castanha-de-sapucaia (Lecythis pisonis Camb.) em várias regióes do Estado de São Paulo (Queiroga Neto et al. 2009; Valillo et al. 1999).

A medida do índice de peróxidos em óleos é utilizada como um indicador dos estágios iniciais de oxidação lipídica. O Codex Alimentarium Commission (2008) estipula para óleos refinados e brutos valores máximos de índice de peróxidos de 10 e 15 meq. $\mathrm{kg}^{-1}$, respectivamente. O óleo analisado apresentou 0 meq. $\mathrm{kg}^{-1}$ de índice de peróxidos. Para o óleo extraído de sementes de baru (Dipteryx alata Vog.) o valor também foi baixo (0,17 meq. $\left.\mathrm{kg}^{-1}\right)$ (Coimbra e Jorge 2010). Altos valores de peróxidos indicam que, de alguma forma, o óleo foi exposto a processo oxidativo quer seja durante o preparo da matéria-prima, extração ou armazenamento do óleo.

O índice de iodo é um teste empírico que indica o grau de insaturação de um óleo. Neste estudo, o óleo das sementes de $P$. aquática Aublet apresentou 27,4 g I $.100 \mathrm{~g}^{-1}$. Segundo estudo realizado por Chaves et al. (2004) verificou-se baixo índice de iodo $\left(66,3 \mathrm{~g} \mathrm{I}_{2} .100 \mathrm{~g}^{-1}\right)$ para o óleo de chichá (Sterculia striata).

O índice de refração está relacionado, principalmente, ao grau de saturação e a razão entre duplas ligaçóes cis/trans dos ácidos graxos, além de sofrer influência de processos oxidativos. No óleo analisado, o índice de refração a $40^{\circ} \mathrm{C}$

Tabela 1 - Composição centesimal das sementes de Pachira aquática Aublet.

\begin{tabular}{lc}
\hline Componentes (\%) & Sementes de $P$. aquática Aublet \\
\hline Umidade & $3,89 \pm 0,07$ \\
Lipídios & $38,39 \pm 0,14$ \\
Proteínas & $11,86 \pm 0,32$ \\
Cinzas & $4,26 \pm 0,24$ \\
Carboidratos e Fibras (por diferença) & 41,60 \\
\hline
\end{tabular}

Média \pm desvio padrão $(n=3)$. foi de 1,4569. Este valor é semelhante ao verificado para óleo comercial como o de palma $(1,454-1,456)$ (Codex Alimentarium Commission, 2008).

$\mathrm{O}$ índice de saponificação indica o peso molecular médio dos ácidos graxos esterificados ao glicerol na molécula de triacilglicerol, ou seja, um índice de saponificação elevado indica ácidos graxos de pesos moleculares baixos e vice-versa. No óleo extraído de sementes de P. aquática Aublet verificouse índice de saponificação de $208 \mathrm{mg}$. KOH g-1. Este valor é comparável aquele reportado pelo Codex Alimentarius Commission (2008) para óleo vegetal convencional como o de palma (190-209 mg.KOH g-1). Quando comparado o índice de saponificaçáo com a literatura, este mostrou-se superior ao óleo da semente de Garcinia mangostana (134 mg.KOH g ${ }^{-1}$ ) (Ajayi et al. 2007) e inferior ao óleo das sementes de Brachystegia eurycoma (251), Tamarindus indica (221 mg.KOH g${ }^{-1}$ ), Mucuna agellipes (229 mg.KOH g${ }^{-1}$ ) (Ajayi et al. 2006).

Já o ponto de fusão de um óleo está relacionado com o número de saturaçóes do mesmo, conferindo-lhe maior ponto de fusão (sólidos à temperatura ambiente). De maneira análoga, os óleos por possuírem um número maior de insaturaçóes, expressam menor ponto de fusão (líquidos à temperatura ambiente). No presente trabalho, o óleo das sementes de $P$. aquática Aublet obteve valor de ponto de fusão $\left(41,9^{\circ} \mathrm{C}\right)$.

Os resultados das análises realizadas indicaram que o óleo possui características físico-químicas semelhantes a óleos comestíveis, como o de palma e amendoim, podendo ser uma nova fonte de óleos para o consumo humano.

A Tabela 3 apresenta os ácidos graxos identificados por cromatografia gasosa, presentes na fração lipídica das sementes de $P$. aquática Aublet. $\mathrm{O}$ perfil de ácidos graxos indica um importante destaque para os ácidos palmítico (44,93\%), oleico $(39,27 \%)$ e o linoleico $(11,35 \%)$. A quantidade total de ácidos graxos saturados foi de $48,93 \%$ e insaturados de $51,08 \%$, dos quais $39,27 \%$ foram de ácidos monoinsaturados e 11,81\% de ácidos poliinsaturados. Dentre os ácidos graxos saturados, o ácido palmítico foi predominante no óleo, seguido pelo

Tabela 2 - Características físico-químicas do óleo das sementes de Pachira aquática Aublet

\begin{tabular}{lc}
\hline \multicolumn{1}{c}{ Características } & Óleo de $P$. aquática Aublet \\
\hline Ácidos graxos livres (\% ácido oleico $)$ & $39,2 \pm 0,17$ \\
Índice de peróxido $\left(\right.$ meq. $\left.^{-1}{ }^{-1}\right)$ & $0 \pm 0,01$ \\
Índice de iodo $\left(\mathrm{g} \mathrm{I}_{2} \cdot 100 \mathrm{~g}^{-1}\right)$ & $27,4 \pm 0,24$ \\
Índice de refração $\left(40{ }^{\circ} \mathrm{C}\right)$ & $1,4569 \pm 0,00$ \\
Índice de saponificação $\left(\mathrm{mg} \cdot \mathrm{KOH} \mathrm{g}^{-1}\right)$ & $208,0 \pm 1,00$ \\
Ponto de fusão $\left({ }^{\circ} \mathrm{C}\right)$ & $41,9 \pm 0,10$ \\
\hline
\end{tabular}

Média \pm desvio padrão $(n=3)$. 
Tabela 3 - Perfil de ácidos graxos presente na fração lipídica das sementes de Pachira aquática Aublet.

\begin{tabular}{lc}
\hline \multicolumn{1}{c}{ Ácidos graxos (\%) } & Óleo de P. aquática Aublet \\
\hline Palmítico (C16:0) & $44,93 \pm 0,12$ \\
\hline Esteárico (C18:0) & $3,08 \pm 0,08$ \\
\hline Oleico (C18:1) & $39,27 \pm 0,16$ \\
Linoleico (C18:2 n-6) & $11,35 \pm 0,10$ \\
Araquídico (C20:0) & $0,87 \pm 0,02$ \\
a-Linolênico (C18:3 n-3) & $0,46 \pm 0,05$ \\
Behênico (C22:0) & $0,05 \pm 0,03$ \\
Saturados & 48,93 \\
\hline Monoinsaturados & 39,27 \\
Poli-insaturados & 11,81 \\
\hline Ole/Lin* & 0,29 \\
\hline Sat/Insat** & 1,04 \\
\hline
\end{tabular}

Média \pm desvio padrão $(n=3)$; *Relação entre o total de ácidos oleico e linoleico **Relação entre 0 total de ácidos graxos saturados e insaturados.

ácido esteárico. Este resultado é coerente com o fato de que o ácido palmítico é o ácido graxo saturado mais abundante nos lipídios vegetais, sendo o ácido esteárico menos comum.

O ácido behênico foi encontrado em baixa porcentagem. Tal fato é desejável uma vez que óleos com altas concentraçôes de ácido behênico podem ser de difícil digestão para humanos e animais, representando sérias implicaçóes para utilização nutricional (Akpinar et al. 2001).

A Figura 1 apresenta o cromatograma da composição de ácidos graxos do óleo extraído das sementes de $P$. aquática Aublet. A qualidade e digestibilidade de óleos vegetais comestíveis são determinadas pela quantidade e composição em ácidos graxos insaturados. A presença de ácido linoleico em teores adequados é fundamental, uma vez que se trata de um ácido graxo essencial. Quanto maior a quantidade de ácido linoleico em relaçáo ao oleico, melhor é a qualidade do óleo vegetal em evitar a formaçáo do mau colesterol (ElAdawy e Taha 2001). A relação ácido oleico /linoleico (Ole/ Lin) obtido para o óleo das sementes foi de 1/0,29. Com relação ao ácido graxo $\alpha$-linolênico $(\mathrm{C} 18: 3 \mathrm{n}-3)$ o óleo das sementes apresentou $0,46 \%$. Levando em consideraçáo a porcentagem desse ácido graxo em óleo comum como o de

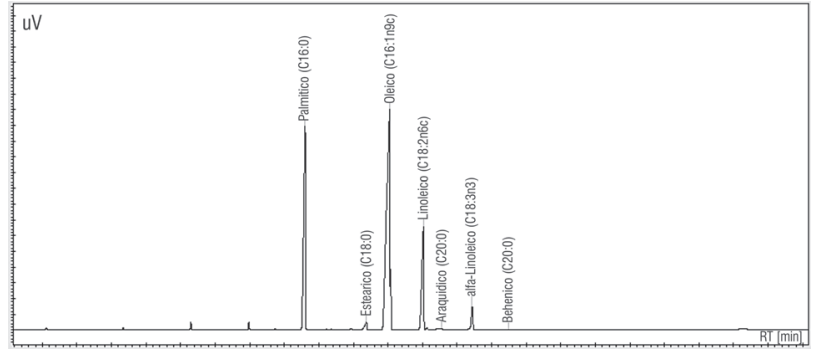

Figura 1 - Cromatograma da composição de ácidos graxos do óleo extraído de Pachira aquática Aublet. girassol (0,3\%) (Codex Alimentarium Commission, 2008), o óleo das sementes de P. aquática Aublet apresenta quantidade considerável de ácido $\alpha$-linolênico.

Comparando-se a relação entre o total de ácidos graxos saturados e insaturados analisado neste trabalho com os citados por Borges et al. (2007) para óleos comuns como amendoim, milho e soja, verificou-se que o óleo das sementes de P. aquática Aublet $(1 / 1,04)$, aproximou-se mais ao óleo de amendoim $(1 / 2,8)$, enquanto que o óleo de soja apresenta $(1 / 5,7)$ e o de milho $(1 / 6,7)$. Quanto menor a relação Sat/Insat, indica que o referido óleo pode ser utilizado em frituras, uma vez que a instabilidade e a rancidez oxidativa estáo relacionadas à quantidade de ácidos graxos insaturados.

A Tabela 4 apresenta as médias para os isômeros $\alpha-, \beta-, \gamma-$, $\delta$-tocoferóis e tocoferóis totais $\left(\mathrm{mg} \cdot \mathrm{kg}^{-1}\right)$ do óleo extraído de P. aquática Aublet. Enquanto o $\alpha$-tocoferol apresenta a maior atividade biológica como vitamina $\mathrm{E}$, o $\gamma$ - e o $\delta$-tocoferol possuem maior atividade antioxidante (Schmidt e Pokorny 2005; Shahidi e Naczk 1995) Desta maneira, o $\gamma$-tocoferol foi o isômero encontrado em maior quantidade neste óleo em estudo, representando $67,60 \%$ do total de tocoferóis no óleo.

A Figura 2 apresenta a média para os isômeros $\alpha-, \beta-, \gamma$-, $\delta$-tocoferóis e tocoferóis totais do óleo extraído de P. aquática Aublet. O teor de tocoferóis totais para o óleo foi de 51,27 mg. $\mathrm{kg}^{-1}$, o que significa em comparação com outros óleos vegetais, que o este óleo não constituem uma boa fonte de tocoferóis. Esta baixa presença de tocoferóis é comum em óleos vegetais altamente saturados, como o óleo de coco (0-50 mg. $\left.\mathrm{kg}^{-1}\right)$ (Codex Alimentarium Commission, 2008). Segundo estudo realizado por Miraliakbari e Shahidi (2008) o teor de tocoferóis totais para o óleo extraído de castanha-

Tabela 4 - Média de tocoferóis no óleo de Pachira aquática Aublet.

\begin{tabular}{lc}
\hline \multicolumn{1}{c}{ Tocoferóis $\left(\mathrm{mg} \mathrm{kg}^{-1}\right)$} & Óleo de $P$. aquática Aublet \\
\hline$\alpha$-Tocoferol & $15,23 \pm 0,10$ \\
$\beta$-Tocoferol & $1,13 \pm 0,03$ \\
Y-Tocoferol & $34,66 \pm 0,21$ \\
D-Tocoferol & $0,26 \pm 0,01$ \\
\hline Tocoferóis Totais & $51,27 \pm 0,28$ \\
\hline
\end{tabular}

Média \pm desvio padrão $(n=3)$.

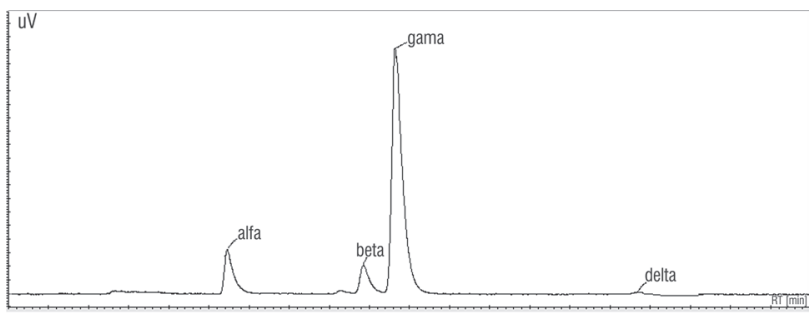

Figura 2 - Cromatograma do teor de tocoferóis do óleo extraído de Pachira aquática Aublet. 
Caracterização do óleo das sementes de Pachira aquatica Aublet para aproveitamento alimentar
do-Brasil (Bertholletia excelsa) foi de 106,80 mg.kg-1. Já Yang (2009) analisou a composição de tocoferóis em óleos extraídos de diversas castanhas, com conteúdos de tocoferóis totais radicalmente diferentes, variando de 452,0 a $60,8 \mathrm{mg} \cdot \mathrm{kg}^{-1} \mathrm{de}$ óleo. A ordem decrescente do nível de tocoferol total foi avelã $>$ amêndoa $>$ nogueira $>$ pistache $>$ pinha $>$ Brasil $>$ pecã $>$ amendoim $>$ macadâmia $>$ caju.

\section{CONCLUSÕES}

O teor de óleo nas sementes de P. aquática Aublet, 38,39\%, demonstrou um bom potencial, indicando a extraçâo do óleo como alternativa para o aproveitamento industrial.

Os resultados das análises físico-químicas indicaram que o óleo possui características semelhantes a óleos comestíveis, como o de palma e amendoim, podendo ser uma nova fonte de óleos para o consumo humano.

Elevadas porcentagens de ácidos graxos foram encontradas no óleo com predominância dos ácidos palmítico, oleico e linoleico. Tal fato favorece o uso deste óleo para fins alimentícios e como matéria-prima para as indústrias farmacêutica e de cosméticos.

\section{AGRADECIMENTOS}

À FAPESP pela concessão da bolsa de Doutorado e ao Conselho Nacional de Desenvolvimento Científico e Tecnológico - CNPq, pela bolsa de Produtividade em Pesquisa.

\section{BIBLIOGRAFIA CITADA}

Ajayi, I.A.; Oderinde, R.A.; Kajogbola, D.O.; Uponi, J.I. 2006. Oil content and fatty acid composition of some underutilized legumes from Nigeria. Food Chemistry, 99: 115-120.

Ajayi, I.A.; Oderinde, R.A.; Ogunkoya, B.O.; Egunyomi, A.; Taiwo, V.O. 2007. Chemical analysis and preliminary toxicological evaluation of Garcinia mangostana seeds and seed oil. Food Chemistry, 101: 999-1004.

Akpinar, N.; Akpinar, M.A.; Turkoglu, S. 2001. Total lipid content and fatty acid composition of the seeds of some Vicia L. species. Food Chemistry, 74: 449-453.

AOAC. 2005. Oficial and Tentative Methods of the AOAC International. Maryland.

AOCS. 2009. Official Methods and Recommended Practices of the American Oil Chemists' Society. Champaign.

Borges, S.V.; Maia, M.C.A.; Gomes, R.C.M.; Cavalcanti, N.B. 2007. Chemical composition of umbu (Spondias tuberosa Arr. Cam) seeds. Química Nova, 30: 49-52.

Brum, M.C.; Santos, L.S.; Santos, R.B.; Lacerda Junior, V.; Greco, S.J.; Castro, E.V.R. Biodiesel da munguba (Pachira aquatica Aubl.): síntese e avaliação da presença de ácidos graxos ciclopropenoídicos. 32a Reunião Anual da Sociedade Brasileira de Química - SBQ, Fortaleza, 2009.
Cahoon, E.B.; Schmid, K.M. 2008. Metabolic engineering of the content and fatty acid composition of vegetable oils. Advances in Plant Biochemistry and Molecular Biology, 1: 161-200.

Cahoon, E.B; Shockey, J.M.; Dietrich, C.R.; Gidda, S.K.; Mullen R.T.; Dyer, J.M. 2007. Engineering oilseeds for sustainable production of industrial and nutritional feedstocks: solving bottlenecks in fatty acid flux. Current Opinion in Plant Biology, 10: 236-244.

Carrero, J.J.; Martín-Bautista, E.; Baró, L.; Fonollá, J.; Jiménez, J.; Boza, J.J.; López-Huertas, E. 2005. Cardiovascular effects of omega-3-fatty acids and alternatives to increase their intake. Nutrición Hospitalaria, 20: 63-69. (in Spanish, with abstract in English).

Cetto, A.A.; Heinrich, M. 2005. Mexican plants with hypoglycaemic effect used in the treatment of diabetes. Journal of Ethnopharmacology, 99: 325-348.

Chaves, M.H.; Barbosa, A.S.; Moita Neto, J.M.; Aued-Pimentel, S.; Lago, J.H.G. 2004. Chemical characterization of the oil of Sterculia striata St. Hil. et Naud nuts. Química Nova, 27: 404408 (in Portuguese, with abstract in English).

Codex Alimentarius Commission. 2008. Codex-Stan 210: codex standard for named vegetable oils. Rome.

Coimbra, M.C.; Jorge, N. 2010. Proximal composition and characterization of baru seed oil. Aceites y Grasas, 78: 614-618 (in Spanish, with abstract in English).

El-Adawy, T.A.; Taha, K.M. 2001. Characteristics and composition of different seed oils and flours. Food Chemistry, 74: 47-54.

Harris, W.S. 2008. The omega-3 index as a risk factor for coronary heart disease. American Journal of Clinical Nutrition, 87: 1997S-2002S.

Hartman, L.; Lago, R.C. 1973. Rapid preparation of fatty acid methyl esters from lipids. Laboratory Practice, 22: 475-476.

Instituto Adolfo Lutz. 1985. Analytical standards of the Institute Adolfo Lutz: chemical and physical methods for food analysis. $3^{\mathrm{a}} \mathrm{ed}$. Sáo Paulo, 533 pp. (in Portuguese).

Lago, R.C.A.; Pereira, D.A.; Siqueira, F.A.R.; Szpiz, R.R.; Oliveira, J.P. 1987. Preliminary study of seed and oil from five species of Amazonian. Acta Amazônica, 16: 369-376 (in Portuguese).

Lavie, C.J. 2009. Omega-3 polyunsaturated fatty acids and cardiovascular diseases. Journal of the American College of Cardiology, 54: 585-594.

Lorenzi, H. 1992. Árvores Brasileiras: manual de identificação e cultivo de plantas arbóreas nativas do Brasil, Editora Plantarum Ltd. São Paulo, Brasil: Nova Odessa.

Miraliakbari, H.; Shahidi, F. 2008. Antioxidant activity of minor components of tree nut oils. Food Chemistry, 111: 421-427.

Oliveira, J.T.A.; Vasconcelos, I.M.; Bezerra, L.C.N.M.; Silveira, S.B.; Monteiro, A.C.O.; Moreira, R.A. 2000. Composition and nutritional properties of seeds Pachira aquatica Aubl, Sterculia striata St Hil et Naud and Terminalia catappa Linn. Food Chemistry, 70: 185-191. 


\section{ACTA} AMAZONICA

Caracterização do óleo das sementes de Pachira aquatica Aublet para aproveitamento alimentar
Paula, V.F.; Cruz, M.P.; Barbosa, L.C.A. 2006. Chemical constituents of Bombacopsis glabra (Bombacaceae). Quimica Nova, 29: 213215 (in Portuguese, with abstract in English).

Peixoto, A.L.; Escudeiro, A. 2002. Pachira aquática (Bombacaceae) na obra "história dos animais e árvores do Maranhão" de Frei Cristóvão de Lisboa. Rodriguésia, 53, 123-130.

Polizelli, P.P.; Facchini, F.D.A.; Cabral, H.; Bonilla-Rodriguez, G.O. 2008. A new lipase isolated from oleaginous seed from Pachira aquatica (Bombacaceae). Applied Biochemistry and Biotechnology, 150: 233-242.

Queiroga Neto, V.; Bora, P.S.; Diniz, Z.N.; Cavalheiro, J.M.O.; Queiroga, K.F. 2009. Dipteryx lacunifera seed oil: characterization and thermal stability. Ciência e Agrotecnologia, 33: 1601-1607.
Schmidt, S.; Pokorny, J. 2005. Potential application of oilseeds as sources of antioxidants for food lipids - a review. Czech Journal of Food Science, 23: 93-102.

Shahidi, F.; Naczk, M. 1995. Food phenolics: sources, chemistry, effects and applications. Lancaster: Technomic, 545 pp.

Vallilo, M.I.; Tavares, M.I.; Aued-Pimentel, S.; Campos, N.C.; Neto, J.M. 1999. Lecythis pisonis Camb. nuts: oil characterization, fatty acids and minerals. Food Chemistry, 66: 197-200.

Yang, J. 2009. Brazil nuts and associated health benefits: a review. LWT - Food Science and Technology, 42: 1573-1580.

Recebido em 06/10/2010

Aceita em 24/01/2011 
